\title{
PSYCHE
}

Vol. 73

September, 1966

No. 3

\section{THREE NEW SPECIES OF ACCOLA (ARANEAE, DIPLURIDAE) \\ FROM COSTA RICA AND TRINIDAD, W. I.*}

\author{
By Arthur M. Chickering \\ Muscum of Comparative Zoology
}

The genus Accola Simon was established in I 889 on the basis of an immature specimen of $A$. lucifuga Simon from Venezuela. During the next thirty-six years eight additional species were recognized. Three of these were from Luzon and New Guinea and all were described from females alone. The remaining five were from St. Vincent, W. I., Panama, Chile and Venezuela. Two of these, one from Venezuela and one from Panama, were described from immature individuals. The remaining three species were all described from females alone. In $1945 \mathrm{I}$ was able to describe the male of A. spinosa Petrunkevitch together with mature females. In 1964 I was able to describe both sexes of $A$. petrunkevitchi from Puerto Rico and both sexes of $A$. lewisi from Jamaica, W. I. During the past few months I have been able to recognize a new species of this genus taken in a recent collection in Costa Rica and two new species in a collection made in Trinidad, W. I. in April, 1964. These lastmentioned three species are described in the following pages of this brief paper. The present status of the Genus Accola Simon, I889 may, therefore, be stated as follows: fourteen species are now recognized; six of these are known from both sexes; two are known only from immature specimens; the remaining six species are known only from females. I think it safe to predict that numerous additional species will become known as soon as careful collecting is carried out in South America and the West Indies. The greater portion of my collection of this genus has come from weed and hay debris with leaf debris considerably less productive.

All specimens relating to the new species described in this paper will be deposited in the Museum of Comparative Zoology at Harvard University. In my study of the genus Accola I have noted irregu-

*Manuscript received by the editor February 24, 1966. 
larities in the outline of certain of the eyes; there seem to be differences in the relative positions of certain of the eyes in some individuals and, apparently, noticeable differences in size of corresponding eyes in certain individuals. When eyes are oval in outline, as they usually appear, the long axis is used in measurements.

The collections from Costa Rica and Trinidad, W. I. from which the three new species of Accola were obtained were made possible by Grant GB-180 I from the National Science Foundation. My gratitude and appreciation are also again expressed for the privilege of working in the Museum of Comparative Zoology at repeated intervals over a period of many years. Publication and library privileges together with continued encouragement from directors and staff members have been indispensable for the continuation of my studies.

\section{Genus Accola Simon, i 889}

Accola downeyi sp. nov.

\section{Figures I-5}

The species is named after Dr. John C. Downey, Professor of Zoology, Southern Illinois University, Carbondale, Illinois.

Male holotype. Total length from clypeus to posterior end of abdomen $3.9 \mathrm{~mm}$; from anterior border of porrect chelicerae to posterior end of abdomen $4.29 \mathrm{~mm}$. Carapace $1.67 \mathrm{~mm}$ long; $1.32 \mathrm{~mm}$ wide opposite second coxae where it is widest; $.44 \mathrm{~mm}$ tall; dorsal striae moderately well developed; dorsal median fovea a well defined pit opposite third coxae; stiff bristles along broad posterior border as usual in the genus; with a recurved row of stiff bristles shortly behind the median fovea; with numerous hairs and stiff bristles elsewhere. Eyes: six only; essentially as in A. lewisi Chickering, I964 from Jamaica, W. I.; all compactly grouped on a low tubercle (Fig. I); viewed from above, posterior row strongly recurved as usual; all eyes white; ratio of eyes ALE : PME : PLE $=$ I I : 5 : II. ALE separated from one another by a little less than one fourth of their diameter; PLE separated from one another behind by slightly less than their diameter; PME separated from one another by about 3/IO of their diameter and from PLE by about one fifth of their diameter. Chitinized clypeus almost non-existent; membranous region below chitinized portion quite conspicuous. Chelicerae: paraxial, parallel, porrect as usual in the genus; fairly robust; with a well developed coat of stiff bristles; fang long, slender, evenly curved; promargin of fang groove with a row of ten teeth; a cluster of very minute teeth, irregularly arranged along the obscure retromargin opposite the last four promarginal teeth (teeth observed on a para- 


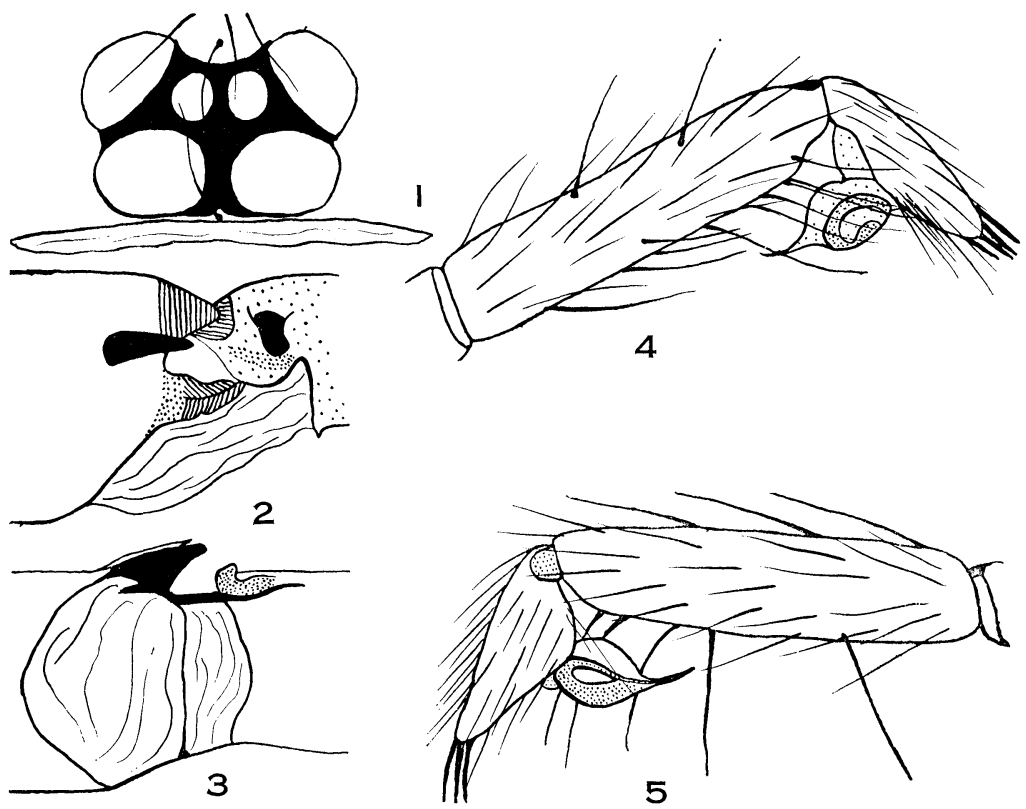

Figs. 1-5. Accola downeyi sp. nov. Fig. 1. Eyes of male as seen from above. Figs. 2-3. Spines and associated parts at articulation of first tibia and metatarsus of male holotype; prolateral and ventral views, respectively. Figs. 4-5. Left palpal tibia and tarsus of male holotype; prolateral and retrolateral views, respectively.

type to avoid injury to fragile holotype); retromargin with a well developed scopula of long, slender hairs or bristles. Lip and sternum: essentially typical of the genus. Legs: 4I23; tibial index of first leg IO, of fourth leg I2. Spines: all legs bear numerous spines essentially as described for $A$. petrunkevitchi Chickering, I964 from Puerto Rico; special spines or cusps at articulation of first tibiae and metatarsi shown in Figures 2-3; numerous trichobothria observed on tibiae, metatarsi and tarsi. Palp: essential features shown in Figures 4-5; coxa with a rudimentary maxillary lobe. Abdomen and color in alcohol: both essentially as described for $A$. spinosa Petrunkevitch (1945); anterior spinnerets very fragile.

Female paratype. Total length from clypeus to posterior end of abdomen $5.33 \mathrm{~mm}$; from distal end of porrect chelicerae to posterior end of abdomen $5.92 \mathrm{~mm}$. Carapace $2.05 \mathrm{~mm}$ long; $1.52 \mathrm{~mm}$ wide opposite second coxae where it is widest; .6 $\mathrm{I} \mathrm{mm}$ tall; otherwise 
essentially as in male. Eyes: six; essentially as in male. Chelicerae: in general as in male holotype; promargin of fang groove with eleven small but clearly defined teeth; the cluster of very minute teeth along obscure retromargin has about 19 or 20 in the group. Lip and sternum: essentially as in male holotype. Legs: 4I23; tibial index of first and fourth legs 12 ; spines essentially as in male; trichobothria observed on tarsi, metatarsi, tibiae and patellae as well as on palpal segments; palpal claw finely dentate. Abdomen: typical of females of the genus; second pair of lungs clearly delineated. Epigynum: with a well defined plate; posterior margin procurved; typical of females of the genus.

Type locality. The male holotype and the described female paratype are from Turrialba, Costa Rica, July 25 to August I 5, 1965. Four male paratypes and about three dozen females and immature specimens were taken in the same general locality and during the same period. In I 945 when I described the mature male and mature female of $A$. spinosa Petrunkevitch $\mathrm{I}$ also had a few mature females from Boquete, Panama with only six eyes. These six-eyed specimens were then regarded as deviates of $A$. spinosa Petrunkevitch as explained in a footnote, page I. Since that time numerous females and three mature males from Boquete and El Volcan, Panama have been collected. These are all six-eyed and agree well with my specimens of Accola downeyi sp. nov. For this reason they are, therefore, transferred to this species.

\section{Accola simla sp. nov. Figures 6-8}

The name of the species is a noun used in apposition after the type locality.

Male holotype. Total length from clypeus to posterior end of abdomen $3.38 \mathrm{~mm}$; from anterior border of porrect chelicerae to posterior end of abdomen $3.64 \mathrm{~mm}$. Carapace $1.52 \mathrm{~mm}$ long; I.I $\mathrm{mm}$ wide opposite second coxae where it is widest; $0.4 \mathrm{~mm}$ tall; other features typical of males of the genus. Eyes: eight essentially as in A. petrunkevitchi Chickering from Puerto Rico; all arranged on a low tubercle (Fig. 6); viewed from above, posterior row strongly recurved; AME dark and difficult to distinguish; all others white; ratio of eyes $A M E: A L E: P M E: P L E=2:$ I I : 6.5 : I0.5; AME separated from one another by about their diameter; only slightly separated from ALE; ALE separated from one another in front by about one sixth of their diameter; PME separated from one another by about one sixth of their diameter; PME separated 

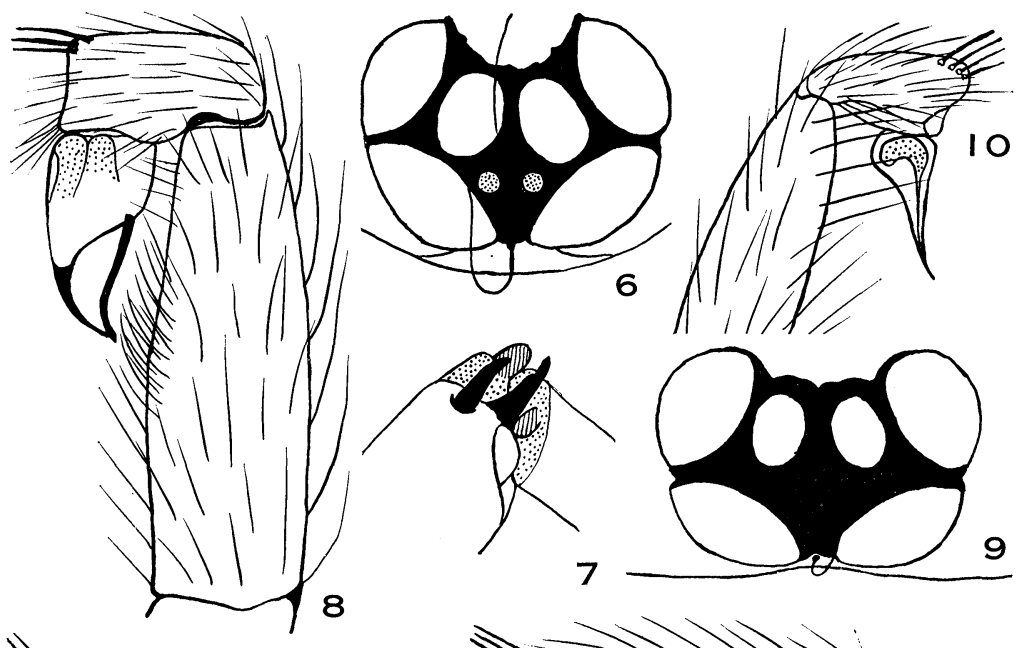

8

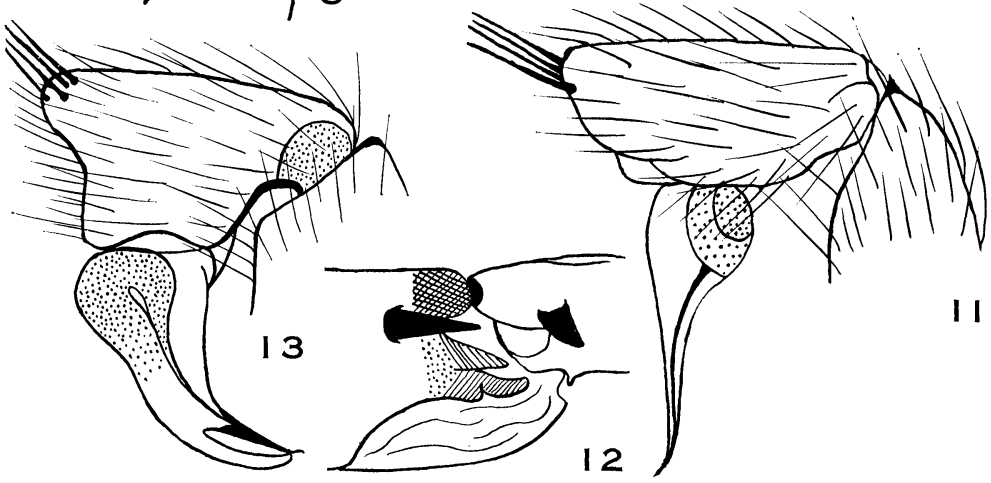

Figs. 6-8. Accola simla sp. nov. Fig. 6. Eyes of male holotype as seen from above. Fig. 7. Spines and associated parts at articulation of first left tibia and metatarsus of male holotype; prolateral view. Fig. 8. Left palpal tibia and tarsus of male holotype; retrolateral view.

Figs. 9-11. Accola barona sp. nov. Fig. 9. Eyes of male holotype as seen from above. Figs. 10-11. Left palpal tibia and tarsus of male holotype; prolateral and retrolateral views, respectively.

Figs. 12-13. Accola spinosa Pet. Fig. 12. Spines and associated parts at articulation of first left tibia and metatarsus of male; prolateral view. Fig. 13. Left palpal tibia and tarsus; retrolateral view. 
from PLE by about one fourth of their diameter; PLE separated from one another behind by about four fifths of their diameter. Chitinized height of clypeus very low and irregular; membranous portion much higher. Chelicerae paraxial, parallel, porrect as usual in the genus; fairly robust; with a well developed supply of stiff bristles; fang long, slender, evenly curved; promargin of fang groove with a row of ten small teeth; along the obscure retromargin, as seen on a paratype, is a row of about 7-8 very minute denticles; retromargin with a well developed scopula of long, slender hair or bristles. Lip and sternum: essentially typical of the genus. Legs: 4I2 $=3$; tibial index of first and fourth legs II. Spines: all legs bear numerous spines essentially typical of the genus; special spines at articulation of first tibiae and metatarsi shown in Figure 7; the most ventral of the tibial spines is probably divided but the two parts are so closely apposed that they appear as one. Palp: essential features shown in Figure 8; bulb terminates in two spines. Abdomen: typical of the genus; with a heavy coat of dark hair. Color in alcohol: as usual in the genus; a unicolorous yellowish.

Female paratype. Total length of female paratype, selected for description, from clypeus to posterior end of abdomen $4.03 \mathrm{~mm}$; from anterior border of porrect chelicerae to posterior end of abdomen $4.42 \mathrm{~mm}$. Carapace $\mathrm{I} .78 \mathrm{~mm}$ long; I.32 $\mathrm{mm}$ wide; $.45 \mathrm{~mm}$ tall; otherwise essentially as in male. Eyes: essentially as in male. Chelicerae: promargin of fang groove with nine small teeth; retromargin with about eleven minute denticles somewhat irregularly arranged; otherwise essentially as in male. Lip and sternum: essentially typical of the genus. Legs: 4I32; tibial index of first and fourth legs I2; spines on legs essentially as usual in the genus. Abdomen: typical of females of the genus; with the usual heavy coat of hairs. Epigynum: with the usual swollen plate, typical of females of the genus. Color in alcohol: as in male.

Type locality. Male holotype and female paratype selected for description taken at Simla, Arima Valley, Trinidad, W. I., April I 5th, and IIth, I964, respectively. Fourteen male paratypes and several dozens of what are believed to be females and immature specimens belonging to this species were taken in same general locality from March 3ist to April 26th, I964.

Accola barona sp. nov.

Figures 9-I I

The name of the species is an arbitrary combination of letters. Male holotype. Total length from anterior border of ALE to 
posterior end of abdomen 3.7 I from anterior border of porrect chelicerea to posterior end of abdomen $3.9 \mathrm{~mm}$. Carapace: $1.69 \mathrm{~mm}$ long; I.2 I mm wide opposite second coxae where it is widest;.34 $\mathrm{mm}$ tall; slightly the highest just behind median thoracic pit; other features typical of the genus. Eyes: six only; no traces of the AME observed; viewed from above, posterior row quite strongly recurved; all six eyes white; ratio of eyes ALE : PME : PLE $=$ I0.5 : 5 :9; ALE separated from one another by about one fifth of their long axis; PME separated from one another by about $3 /$ IO of their long axis and separated from PLE by somewhat less than this; PLE separated from one another behind by a little less than their long axis. Height of clypeus equal to about $\mathrm{I} / 7$ of the long axis of ALE. Chelicerae: essentially as described for $A$. simla sp. nov.; teeth and denticles along fang groove seem to be much as in $A$. simla sp. nov. but they have not been closely observed because of the fragility of the holotype and absence of male paratypes. Lip and sternum: essentially typical of the genus. Legs: 4I ?23; tibial index of fourth leg I 2. Spines: ordinary spines on legs appear typical of the genus; first legs missing and, hence, no record possible in respect to the special spines at articulation of first tibiae and metatarsi. Palp: essential features shown in Figures IO-II. Abdomen: typical of males of the genus. Color in alcohol: as usual, unicolorous yellowish throughout.

Female paratype. Total length of female paratype selected for description $4.23 \mathrm{~mm}$ from clypeus to posterior end of abdomen; from anterior border of porrect chelicerae to posterior end of abdomen $4.68 \mathrm{~mm}$. Carapace $1.63 \mathrm{~mm}$ long; I.I7 mm wide opposite second coxae where it is widest; about $.46 \mathrm{~mm}$ tall; other features as usual in females of the genus. Eyes: six as in male holotype; ratio of eyes ALE : PME : PLE $=8: 4: 6.5$; other features essentially as in male holotype. Chelicerae: general features as usual in the genus; the second female shows promargin of fang groove with about twelve teeth, those in IIth and I2th places the largest; the retromargin has a well developed scopula and a row of a dozen or more very minute denticles irregularly arranged. Legs: $4 \mathrm{I} 2=3$; tibial index of first leg II, of fourth ley I2; with many spines as usual; tarsal claws finely and multidentate. Abdomen: as usual in the genus. Epigynum: with the usual somewhat thickened plate and the procurved posterior border. Color in alcohol: unicolorous yellowish as usual.

Type locality. Male holotype and described female paratype together with one additional somewhat damaged female all taken from 
grass and weed debris in the immediate vicinity of the William Beebe Tropical Research Station, Simla, Arima Valley, Trinidad, W. I., April 23, 1964.

\section{Accola spinosa Petrunkevitch}

Figures I2-I3

As pointed out in the last paragraph of my description of $A$. downeyi sp. nov., all six-eyed specimens now in my collection of the genus Accola from Boquete and El Volcan, Panama are transferred to $A$. downeyi sp. nov.

Since the publication of my paper on this species in I945 I have collected a large number of both sexes in the Panama Canal Zone and, especially, on Barro Colorado Island. Females as expected, far outnumber males. In order to make the distinction clearer between this species and other eight-eyed forms such as $A$. petrunkevitchi Chickering from Puerto Rico and $A$. simla sp. nov. from Trinidad I am including Figures I2-13. Special attention is directed to Figure I2 which shows the division of the most ventral of the spines at the distal end of the first tibia. This division was noted in my 1945 description. There is some variation in the appearance of these spines among males of this species; apparently in some specimens the two spines overlap to such an extent as to obscure one of them. Disarticulation of the first tibia and metatarsus reveals the division more clearly.

\section{SELECTED BibLiography}

Bonnet, $\mathbf{P}$.

1955. Bibliographia Araneorum. Toulouse, Vol. 2 (2).

Chickering, Arthur M.

1945. Hypotypes of Accola spinosa Petrunkevitch (Dipluridae) from Panama. Trans. Connecticut Acad. Arts and Sciences, 36: 159-167.

1964. Two New Species of the Genus Accola (Araneae, Dipluridae). Psyche, $71(4)$ : 174-180.

Petrunkevitch, A.

1925. Arachnida from Panama. Trans. Connecticut Acad. Arts and Sciences, 27: 51-248.

ROEWer, C. Fr.

1942. Katalog der Araneae. 1: 1-1040.

Simon, Eugene

1892- Histoire naturelle des Araignées. Deuxième Edition.

1903. 2. Librarie Encyclopédique de Roret, Paris. 

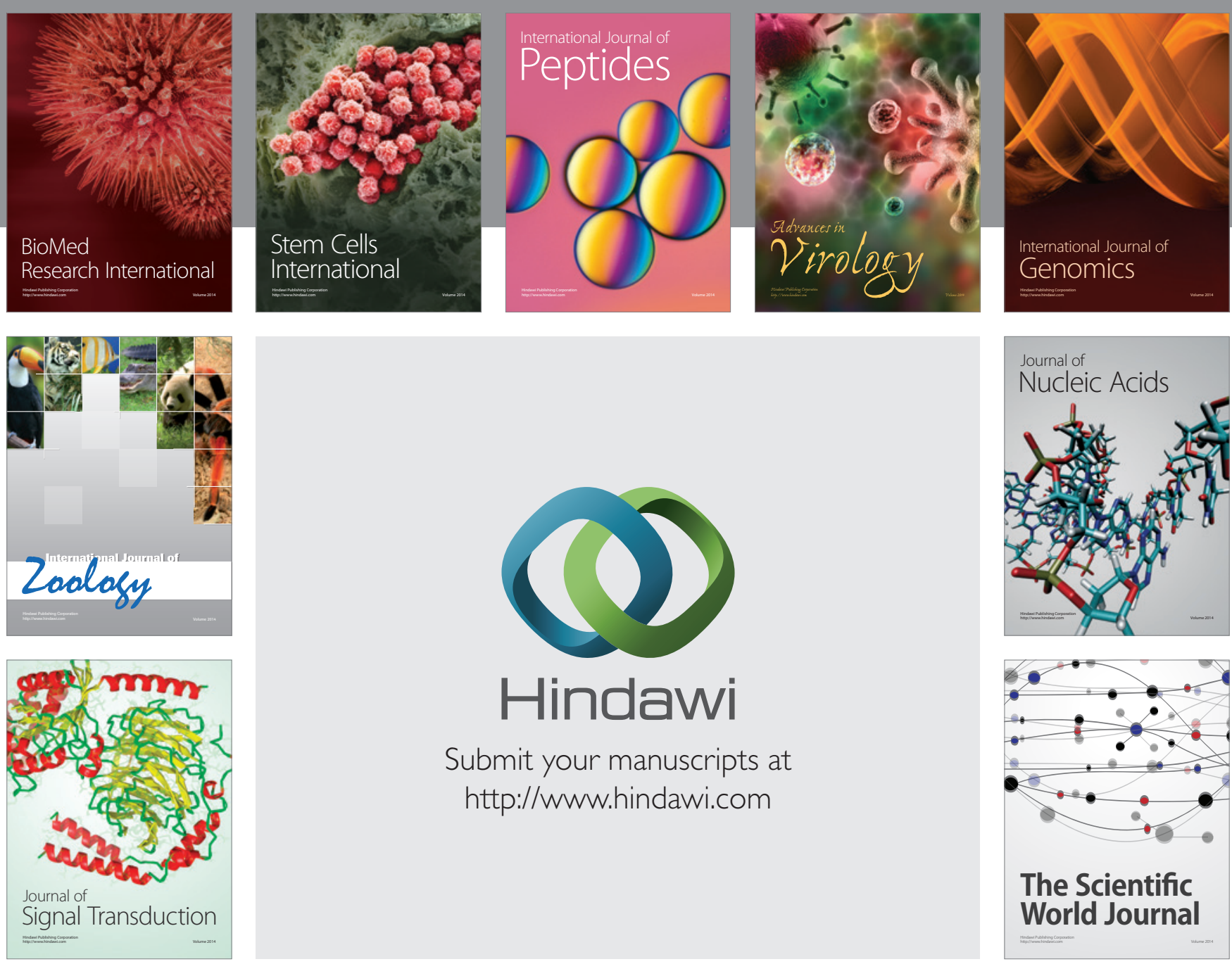

Submit your manuscripts at

http://www.hindawi.com
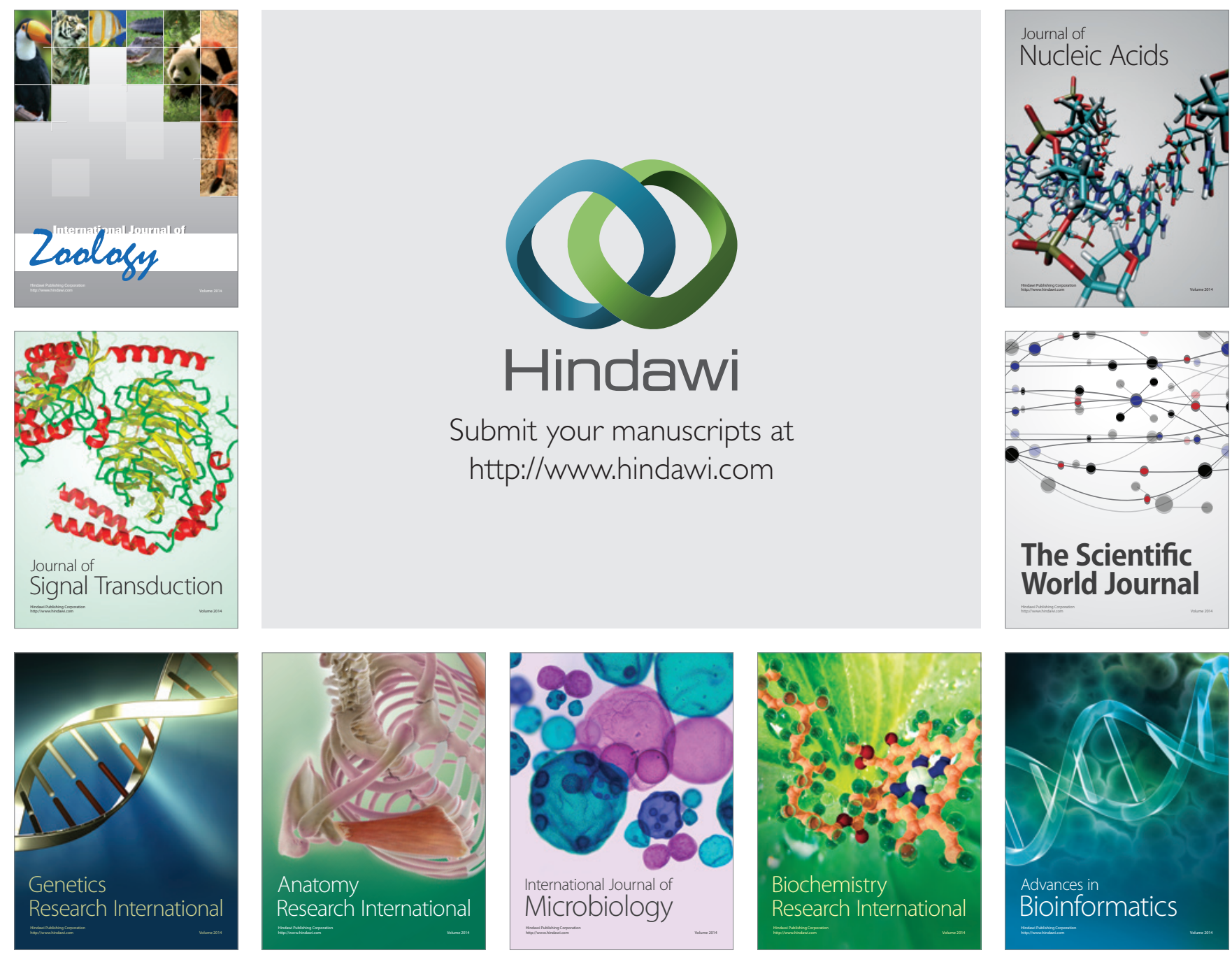

The Scientific World Journal
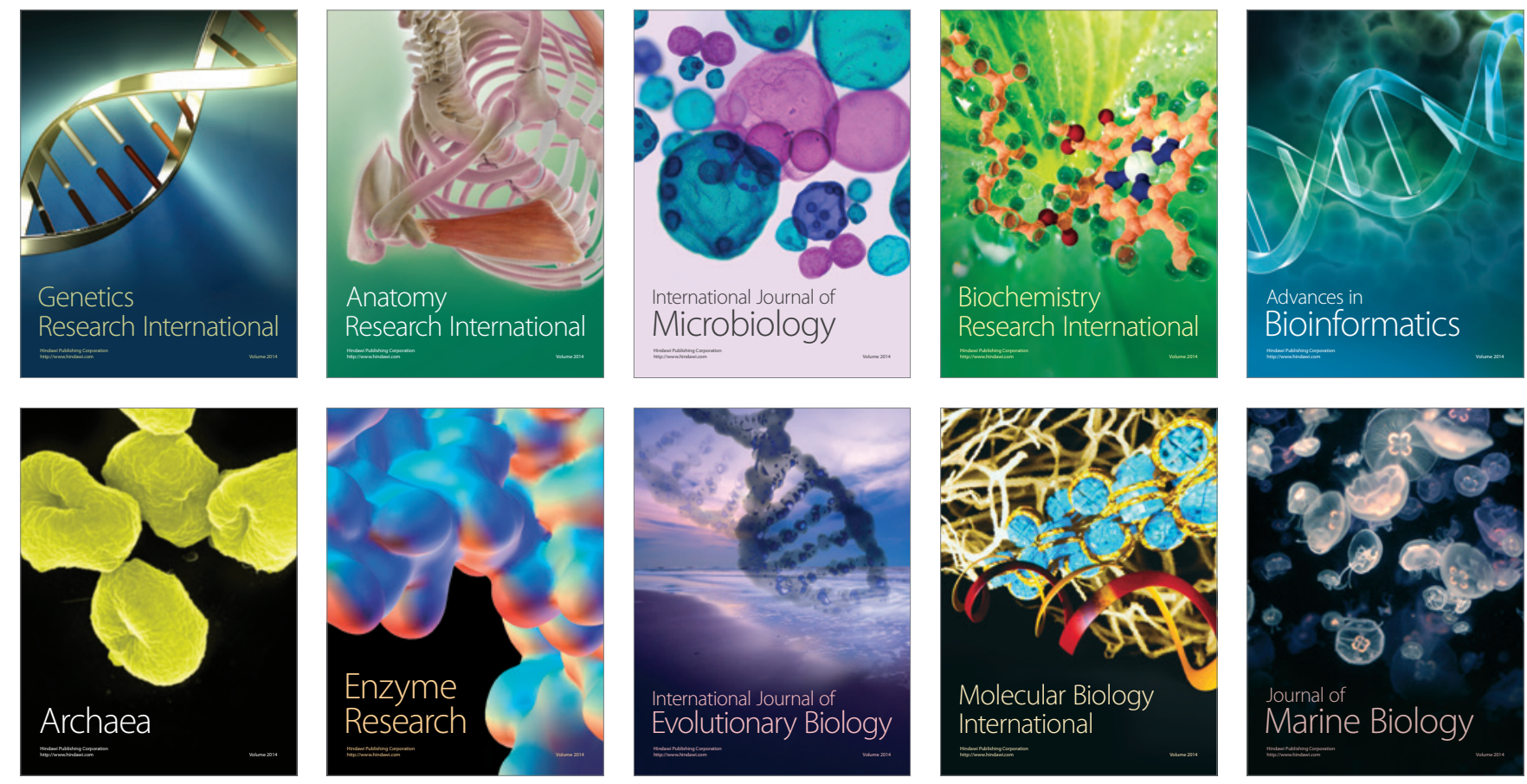